\title{
APLICAÇõES DE 3D LASER SCANNING PARA UM (RE) INVENTÁRIO DIGITAL DO PATRIMÔNIO CULTURAL EDIFICADO DE MONTE SANTO, BAHIA
}

\author{
3D LASER SCANNING APPLICATIONS FOR A DIGITAL (RE) INVENTORY OF THE BUIL X \\ CULTURAL HERITAGE OF MONTE SANTO, BAHIA
}

\author{
Regina Andrade Tirello ${ }^{1}$ e Timóteo de Andrade Ferreira ${ }^{1}$
}

\section{RESUMO:}

Estudos documentais sobre conservação do patrimônio edificado e reconhecimento da estratificação da morfologia urbana de sítios históricos brasileiros, visando contribuir com a preservação de sua materialidade, imagem e significados culturais, representam temática de crescente interesse científico. Neste artigo, para reflexões sobre procedimentos de inventariação da herança cultural, toma-se como objeto de análise exemplar a cidade de Monte Santo, Bahia, reconhecida em 1983 pelo Instituto do Patrimônio Histórico e Artístico Nacional (IPHAN) como patrimônio nacional pelo seu valor paisagístico, arquitetônico e histórico. Passados trinta e sete anos, a adulteração física da cidade tem sido crescente, expondo a riscos seus valores de integridade ambiental. Para viabilizar novos registros documentais da condição dos logradouros, arquitetura histórica e monumentos tombados em uma cidade de topografia e superfícies complexas, adotouse como ferramenta complementar escaneamentos a laser terrestre com tecnologia LiDAR. $O$ emprego do 3D Laser Scanning possibilitou a obtenção de informações tridimensionais qualitativas e métricas, que viabilizaram o reconhecimento preliminar de inteiros trechos urbanos $\left(488.000 \mathrm{~m}^{2}\right)$ e de monumentos possibilitando documentação das alterações e permanências do território e do estado de integridade de suas construções.

PALAVRAS-CHAVE: 3D Laser Scanning; Patrimônio Cultural Arquitetônico; Documentação do Patrimônio Construído; Inventário da Paisagem Cultural.

\begin{abstract}
:
Studies on the built-heritage conservation as well as the acknowledgment of urban morphology stratification aiming at preserving its materiality, image and meanings, refer to an increasing scientific interest theme. The present research has as an object of study the city of Monte Santo, in the state of Bahia. In 1983, the site was acknowledged by the National Institute of Historic and Artistic Heritage (IPHAN) as a national heritage due to its landscape, architectural and historical value. After thirty-seven years, the historical site has been increasingly damaged, which puts its historical environment at risk. In order to provide new document registries of street network, street block organization and architectural typology of a city with complex topography and surfaces, we have chosen to use terrestrial laser scanner with LiDAR technology. The use of 3D Laser Scanning permitted to obtain qualitative tridimensional information and accurate metrics that make achievable the construction of complete urban stretches $(488.000 \mathrm{~m} 2)$ as well as of singular buildings, proposing to recognize and register changes and continuity of the territory as well as the integrity of its buildings.
\end{abstract}

KEYWORDS: 3D Laser Scanning; Architectural Cultural Heritage; Documentation of Built Heritage; Cultural Landscape Inventory.

How to cite this article:

TIRELLO, R. A.; FERREIRA T. A. Aplicações de 3D laser scanning para um (re) inventário digital do patrimônio cultural edificado de Monte Santo, Bahia. Gestão \& Tecnologia de Projetos. São Carlos, v16, n3, 2021. https://doi.org/10.11606/gtp.v16i3. 174786
Conflito de Interesse:

Declara não haver.

Ética em Pesquisa:

Declara não haver

necessidade.

Submetido em: 15/09/2020

Aceito em: 20/11/2020 


\section{INTRODUÇÃO}

Toda ação visando a proteção e valorização do patrimônio cultural de um povo depende do reconhecimento dos acervos que o expressa, sejam esses materiais ou imateriais (UNESCO, 2005, p. 14). Entre as medidas de salvaguarda dessa herança a pesquisa histórica e a documentação estão entre as primeiras estratégias para entender "o que existe", "quem o faz" e "porque o faz". Para além do arrolamento de edificações, as sistemáticas de inventariação de um sítio histórico devem atender a procedimentos metodológicos de documentação e registros que promovam efetivamente a compreensão das articulações existentes entre valores tangíveis e intangíveis, evitando-se problemas de incompatibilidade de expectativas entre comunidade, órgãos reguladores e gestores.

A forma de registrar e "explicitar as transformações de que são passíveis os objetos do patrimônio arquitetônico ao longo do tempo, tanto sob o ponto de vista da deterioração como aquelas relativas às intervenções de restauração ou substituição" é questão que permeia o aperfeiçoamento das práticas preservacionistas brasileiras (ALMEIDA; TIRELLO, 2009, p. 4). Nesta perspectiva, a documentação do patrimônio construído com auxílio de recursos digitais para estudos sobre condições de conservação material de conjuntos edificados, associados ao reconhecimento da estratificação da morfologia urbana dos sítios em que se inserem, representa atualmente temática de crescente interesse científico para diversos campos do conhecimento.

Mais que contribuir para instrução de ações de conservação e restauração arquitetônica - a aplicação mais recorrente -, a documentação digital dos espaços urbanos conformados no decurso do tempo pode propiciar entendimentos relevantes sobre processos sócio-históricos de formação e evolução das cidades e, principalmente, sobre suas alterações consideradas desarmônicas, decorrentes de dinâmicas culturais diversas que reconfiguram materialidades e significados memoriais. Por interferirem nas paisagens construídas e na apreensão de sua historicidade, a análise das motivações e da qualidade dessas mudanças é considerada tão relevante quanto a das expressões estéticas da arquitetura tradicional preexistente.

Longe de evocações saudosistas, na contemporaneidade a preservação da herança cultural, em suas diversas escalas de complexidade, é considerada "uma notável função urbana e a fruição do patrimônio como algo decorrente do direito à cidade. A preservação de um bem cultural, portanto, repousaria na condição de emanar inteligibilidade histórica" (VIEGAS; TEIXEIRA, 2017, p. 28).

O documento intitulado "Princípios para registro de monumentos e grupos de edifícios e sítios" i, exarado em 1996 na 11 a Assembleia Geral do ICOMOS (International Council on Monuments and Sites) à luz das recomendações da Carta de Veneza, 1964 (os princípios internacionais basilares da conservação e do restauro), traz claras recomendações para o registro de bens culturais em perspectiva preservacionista. Enfatizando a importância das colaborações interdisciplinares para compreensão da natureza do patrimônio cultural, reafirma o papel da documentação referenciada por dados históricos como uma das instâncias legítimas de preservação da herança dos povos. Nesta direção, o registro de bens culturais está longe de ser uma atividade meramente tecnicista.

O registro é a captura de informações que descrevem a configuração física, a condição e o uso de monumentos, grupos de edifícios e locais, em momentos específicos, e é uma parte essencial do processo de conservação. [...] Registros de monumentos, grupos de edifícios e locais podem incluir evidências tangíveis e intangíveis, e constituem uma parte da documentação que pode contribuir para a compreensão do patrimônio e seus valores relacionados. (ICOMOS, 1996, p 49). 
Sob o ponto de vista físico a história de uma cidade pode ser também analisada na escala dos detalhes, a exemplo da composição das tramas construtivas dos prédios históricos, que se oferecem como fontes indiciais para interpretação de diversas mudanças urbanas não documentadas convencionalmente.Quando a estratificação originada por intervenções sucessivas dá lugar a desorganização espacial, ou a fachadas incongruentes, é preciso reavaliar as caraterísticas e o impacto dessas mudanças para os valores de ambiência histórica que se quer salvaguardar.

Tendo por base tais reflexões sobre a inevitabilidade de atualizar procedimentos de registro e inventariação do patrimônio construído, este artigo apresenta parte de resultados de experiências de documentação digital realizada com varreduras laser scanner terrestre (Territorial Laser Scanning) de pequena cidade localizada no sertão da Bahia, reconhecida como patrimônio nacional: Monte Santo.

A cidade de Monte Santo da Bahia abriga o secular santuário "Serra da Santa Cruz", tombado pelo Serviço de Patrimônio Histórico e Artístico Nacional (SPHAN, atual IPHANii) em 1983 como patrimônio brasileiro,pelo seu valor paisagístico, arquitetônico e histórico. Fundamentando-se em processo de inventariação primordial de reconhecimento do acervo cultural da cidade, o tombamento deste sítio representou uma ação pioneira de acautelamento legal para preservar o patrimônio material e a cultura popular sertaneja consecutivamente.

Passados trinta e sete anos deste tombamento modelar são muitas as adulterações físicas que se observam atualmente nos bens e áreas protegidas de Monte Santo. Correspondem a mudanças substanciais que solicitam uma nova e ampla campanha de documentação propiciadora de reavaliações formais e técnicas da cidade configurada na contemporaneidade. Sítios históricos não são independentes dos grupos sociais que neles vivem e os transformam; novas práticas e usos não planejados do tecido construído terminam interferindo na disposição dos espaços e, consequentemente, na percepção da ambiência histórica, que por sua vez envolve aspectos físicos e subjetivos. Nessa perspectiva, ainda que mudanças não planejadas por vezes signifique descaracterização da arquitetura antiga, o reconhecimento da qualidade e características das "novas feições" que essa cidade vem adquirindo no decurso do tempo é trabalho imprescindível para o planejamento de futuras ações eficientes para assegurar a permanência de seus valores culturais distintivos. 0 desafio da preservação de Monte Santo associa-se, portanto, à ampliação da leitura do próprio sítio tombado, 'propiciadora de melhores interações entre os aspectos natural e cultural, material e imaterial desse lugar, para que, com estratégias integradas de intervenção, seja possível atuar na sua conservação continuada.

O (re) inventário tridimensional de identificação, cuja sistemática, estruturação e resultados apresentam-se parcialmente neste artigo, integra pesquisa de mestrado acadêmico ${ }^{i i i}$ que teve como objetivo central colaborar com a atualização e ampliação das informações sobre a arquitetura histórica de Monte Santo, reunidas pelos órgãos preservacionistas baianos nos estudos de inventariação e tombamento que empreenderam em décadas passadas. Pesquisa que se configura em trabalho preliminar de recolha sistemática de dados atuais sobre o sítio histórico e, atendendo as prerrogativas do universo preservacionista, associa pesquisas bibliográficas, documentais arquivísticas e iconográficas à levantamentos métricos e imagéticos auxiliados por equipamentos digitais de alta performance.

Para melhor analisar a configuração contemporânea de Monte Santo, incluindo suas transformações, positivas ou não, neste estudo os espaços e edifícios selecionados para registros digitais corresponderam àqueles circunscritos a área delimitada na poligonal de tombamento do SPHAN-Ba nos anos 1980: arruamento e casario do núcleo histórico (e suas áreas envoltórias) e as construções seculares presentes na Via Sacra do Monte da Santa Cruz, que corresponde a própria Serra de Piquaraçá (Figura 3b). Esses bens patrimonializados 
haviam sido parcialmente cadastrados no passado, por meio de levantamentos métricos convencionais e com o registro basilar, em fichas de papel, de alguns imóveis exemplares selecionados.

A singularidade das tipologias edilícias, as características topográficas e morfológicas de Monte Santo e a complexa interpenetração tridimensional de seus espaços históricos - envolvendo formas curvas e irregulares de caminhos esculpidos nas rochas-, solicitavam o emprego de instrumentação de alta performance para viabilizar registros digitais que dessem conta da topografia, geometria, cores, materiais construtivos e constitutivos, i e fenômenos degenerativos do conjunto edificado, possibilitando a efetivação de análises técnicas.

A atualização das ferramentas digitais e tecnologias de levantamento aplicáveis ao estudo da arquitetura vem apresentando sempre melhores alternativas de mensuração e possibilidades de avaliação de bens culturais. Nesta pesquisa teve-se a oportunidade trabalhar com equipamento portátil e de grande precisão para o escaneamento de grandes áreas, o Faro FOCUS S 70 ${ }^{\text {iv }}$, com tecnologia LiDAR (Light Detection And Ranging), um método direto de captura de dados, em que o laser se constitui em fonte própria de energia. A distância é determinada medindo o tempo entre a emissão do pulso e o registro da reflexão pela superfície, gerando como produto uma nuvem de pontos com coordenadas tridimensionais.

A nuvem de pontos que foi gerada pelo 3D Laser Scanning em Monte Santo, incorpora dados sobre os arruamentos, a organização das quadras, implantação, morfologia e detalhes de edifícios antigos e novos, sendo no âmbito desta pesquisa matriz e núcleo agregador de diversos conjuntos de dados a serem trabalhados em múltiplas direções. A nuvem permite, por um lado, elaborações de estruturas edificadas bastante complexas que se oferecem a diversas leituras interpretativas e aprofundamentos (da morfologia ao detalhe técnico) e, por outro lado inúmeras explorações a partir de informações heterogêneas de interesse às áreas de conhecimento que confluem para o campo ampliado da conservação de bens culturais.

Tendo como escopo dar início a processo de (re)inventariação do núcleo histórico tombado, o objetivo da "prospecção tridimensional" auxiliada por Scanning Laser, neste estudo, não foi o de produzir modelos e representações fotorrealistas dos edifícios e lugares, apesar de terem sido possibilitadas e usadas em avaliações específicas. A volumetria obtida nos primeiros processamentos de dados, com alto grau de estruturação espacial dos edifícios escanerizados, constitui-se, por si só, em leitura preliminar da trama urbana e construtiva de Monte Santo, inaugurando série de muitas outras explorações e aplicações específicas, possibilitadas pela nuvem de pontos obtida de área correspondente a $488.000 \mathrm{~m}^{2}$.

\section{MONTE SANTO E O SACRO MONTE. O QUE MUDOU DESDE SEU PRIMEIRO INVENTÁRIO?}

A pequena cidade de Monte Santo, localizada no sertão da Bahia, aos pés da Serra Piquaraçá, abriga o antigo "Santuário Serra da Santa Cruz" - o Sacro Monte -, a 490 metros do nível do mar, cuja origem remonta ao século XVIII. Esse altíssimo monte é cenário e lugar de uma Via Crucis (Via Sacra) composta por um caminho de pedras longo $2 \mathrm{~km}$ até o cume da serra, com 25 capelas distribuídas por toda sua extensão. É inspirado na tradição italiana que tenta recriar um monte sacro (o Monte Calvário) com os passos de Cristo, sendo o da cidade de Monte Santo um dos marcos mais importantes de movimentos de peregrinação religiosa no Brasil (Figura 3a).

Cidade e morro são circundados por singular paisagem natural evocativa de fortes memórias históricas, políticas e culturais sertanejas.Entre as memórias que lhe são associadas está a de 
ter sido território da Guerra de Canudos (1896-1897), o conflito sangrento entre o exército brasileiro e os seguidores do beato Antônio Conselheiro, que dizimou milhares de sertanejos.

Esse conjunto singular fez com que a Serra da Santa Cruz fosse reconhecida em 1983 pelo IPHAN-Ba como patrimônio brasileiro por seu valor paisagístico, arquitetônico e históricov. A época tal abrangência significou uma ação excepcional de salvaguarda de bens culturais. Ao englobar a paisagem natural e a arquitetura, tidas como interdependentes na formação da ambiência histórica do lugar, preservou o patrimônio material e a cultura popular, antecipando reflexões que viriam a ser consolidadas no Art. 216 da Constituição Brasileira de 1998 vi (BRASIL, 1988, p. 126). Funda-se assim o "Parque da Santa Cruz de Monte Santo".

O tombamento intituído na cidade de Monte Santo, visando a proteção do núcleo urbano edificado e de seu Sacro Monte, foi resultado direto da implementação dos chamados "inventários de reconhecimento", um instrumento técnico ativado no final dos anos 1970, que para além da tarefa de identificação de monumentos singulares se propôs a identificação e reconhecimento do patrimônio arquitetônico e urbanístico do estado da Bahia.

Até aqueles anos priorizava-se a conservação de edifícios isolados. 0 projeto "Inventário de Proteção do Acervo Cultural da Bahia" (IPAC-Ba) vii propôs, e implementou, levantamentos sistemáticos dos bens de interesse de todo o estado da Bahia que pudessem vir a servir de base ao planejamento urbano-territorial.Foi trabalho pioneiro que correpondeu a extensa identificação patrimônio arquitetônico e artístico baiano, promovendo por meio de ações técnicas planejadas um expressivo alargamento do significado de herança cultural, que o tombamneto de Monte Santo bem exemplifica.

"Conservar o santuário é, não apenas um dever de preservação da cultura,
mas, principalmente, um ato de valorização do homem da terra, um gesto de
sensibilidade, uma manifestação de respeito à terra santa das capelinhas e à
terra santa da alma humana dos seus devotos." (SPHAN/DTC - Processo No
1.060-T-82, 1983, p. 4).

O projeto de inventário das cidades baianas previa atualizações, um intento que não se consolidou, salvo estudos ocasionais. São muitas as lacunas de conhecimento sobre as cidades históricas da Bahia, em especial no que tange às suas condições de conservação. Ainda há muito por fazer no âmbito da documentação patrimonial.Destaca-se que sob o ponto de vista dos bens tangíveis, apesar da excelência do processo de inventariação conduzido naqueles anos, dada a extensão da empreitada e das condições técnicas contingentes de levantamento instrumental com as quais se contava no período, nem todos os edifícios das cidades protegidas pelo tombamento foram objeto de desenho cadastral e fotografias detalhadas.

Tombar não é congelar e, o ato em si, não é garantia de conservação física dos bens tangíveis. Cumpre esclarecer que o tombamento é um instrumento técnico-jurídico de acautelamento, que entre outras providências cria "obrigações para os proprietários de bens tombados, para o poder público e para a sociedade em geral, de manter e conservar o bem cultural" (RABELLO, 2005, p. 77). Idealmente, para que houvesse fiscalização e orientação das formas de preservar materialmente os bens, os órgãos de tutela deveriam ser dotados de recursos financeiros (e não o são), bem como, no caso de sítios históricos, o interesse público urbanístico, regulamentado pelo planejamento urbano, deveria se associar ao interesse público de proteção do patrimônio cultural, o que raramente ocorre no Brasil. 
Figura 1: (a) Vista da cidade Monte Santo a partir da Via Sacra, 1946. (b) Vista antiga do início da Via Sacra que sobe a Serra de Picaraçá, a partir da Rua Senhor dos Passos, 1920. (c) A mesma tomada da imagem $b$ em 2018, explicitando as alterações operadas nos logradouros tombados pelo SPHAN em 1983.

Fonte: (a) Arquivo Fundação Pierre Verger, 1946. (b) Arquivo Hidelgado Cordeiro, 1943. (c) Timóteo de Andrade Ferreira, 2018.

Figura 2: Vista do início da Rua Senhor dos Passos a partir da Praça da Matriz em 2019. Nuvem de

pontos tratada no software RECAP para análise, reprodução e modelagem.

Fonte: Timóteo de Andrade Ferreira, 2019.
Aplicações de 3D laser scanning para um (re) inventário digital do patrimônio cultural edificado de Monte Santo, Bahia.
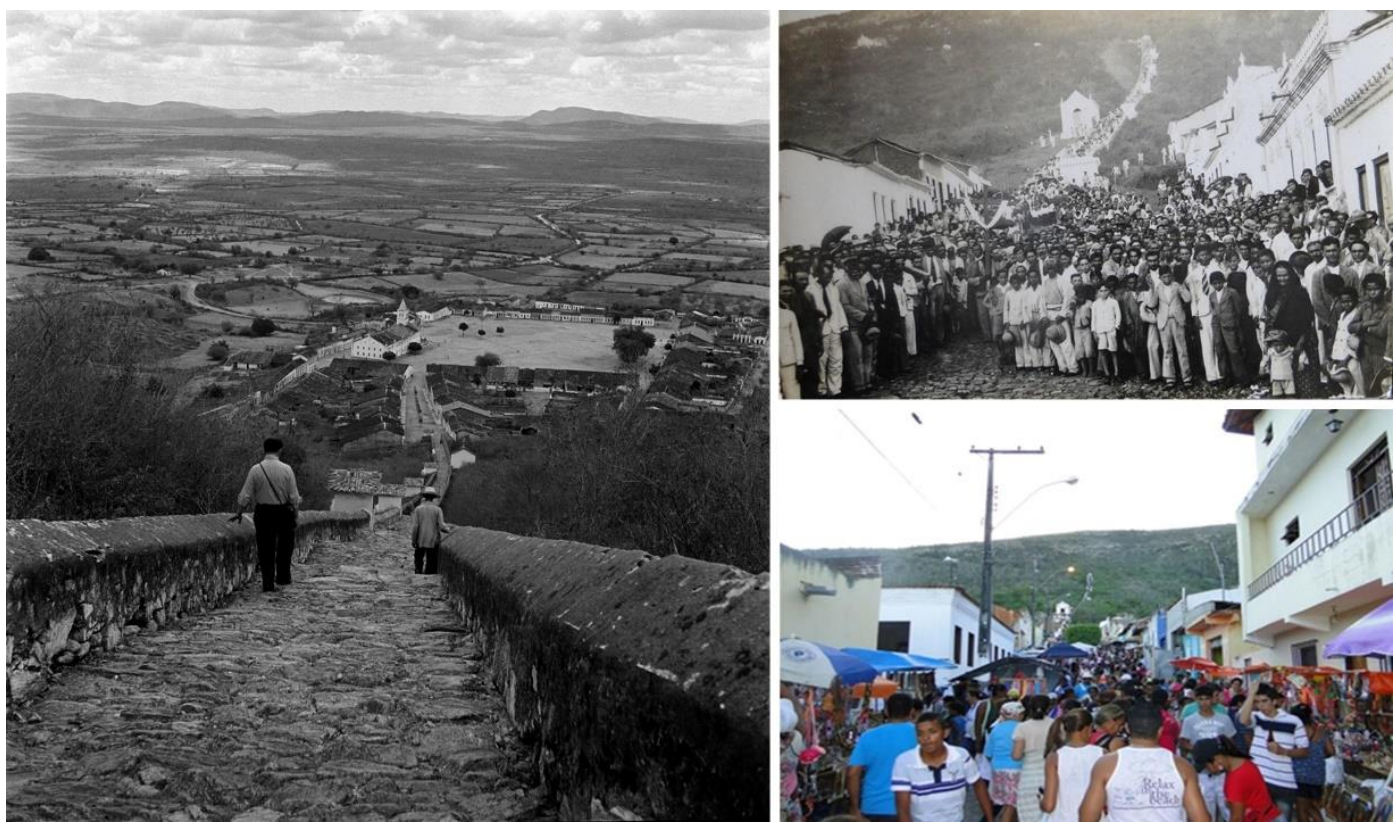

As mudanças radicais das fachadas, as alterações indevidas de gabarito das edificações antigas dos logradouros tombados que conduzem à subida da monumental Via Sacra, são as descaracterizações mais evidentes do conjunto histórico que os "valores de contemporaneidade" estenderam também a outros locais da cidade. (Figura 1). Na Praça da Matriz, área envoltória do núcleo tombado e espaço tradicional da feira da cidade, observa-se a inserção caótica de equipamentos públicos por parte da municipalidade para "modernizar" o que lhes parece arcaico; hoje "a Matadeira" de Canudos viii disputa espaço com uma concha acústica de má qualidade. No entorno da praça vem aumentando a construção de pequenos prédios para acomodar o turismo religioso, para o qual a Casa dos Romeiros (edifício tombado) há muito deixou de ser suficiente e acessível. Trata-se de conjuntos de ações descoordenadas que interferem no desenho dos logradouros, evidenciando a falta de um plano mínimo de tutela para a conservação desse particularíssimo patrimônio nacional (Figura 2).

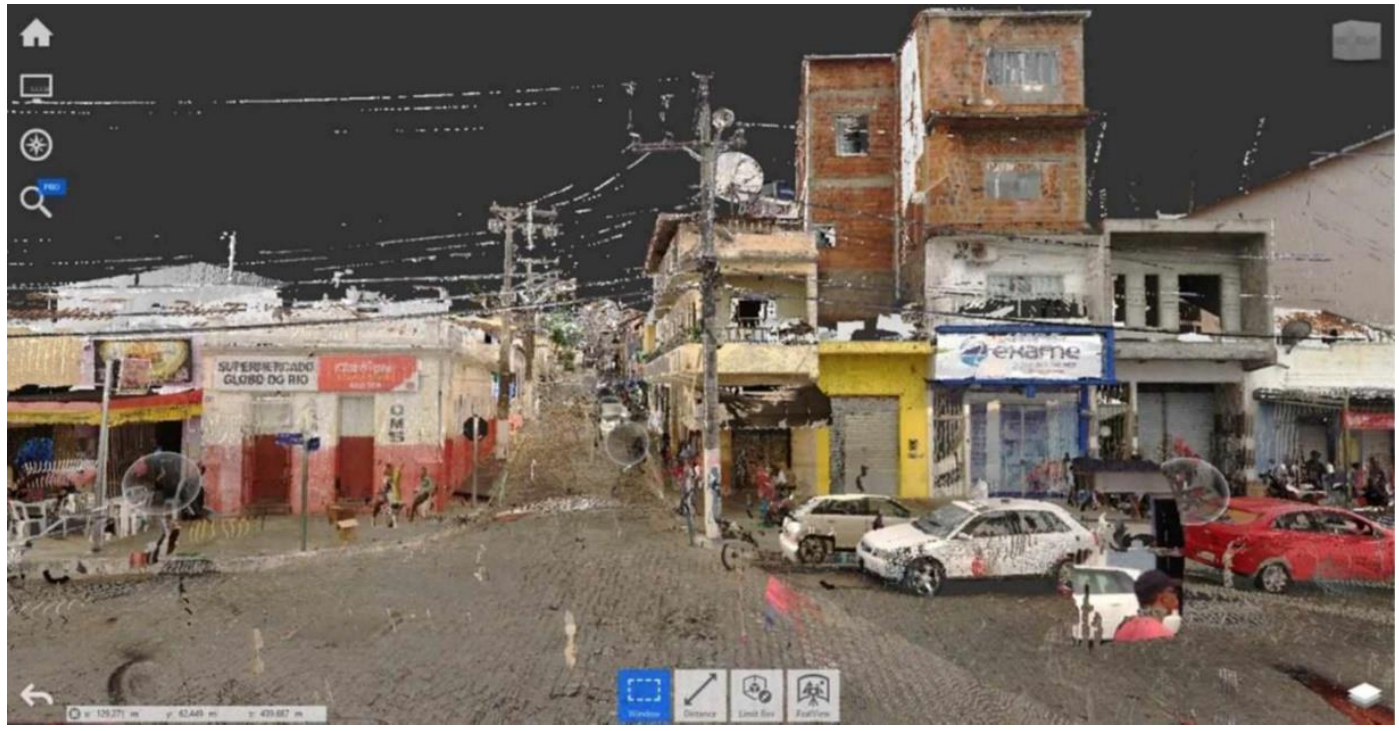




\section{O QUE HÁ PARA (RE) INVENTARIAR EM MONTE SANTO A PARTIR DE SUA POLIGONAL TOMBAMENTO?}

"Inventário" corresponde a um dos instrumentos da preservação. Sob o ponto de vista prático, inventários de bens culturais dizem respeito a identificação e registro de um determinado objeto/lugar, baseando-se em pesquisas e levantamentos de suas características e singularidades. A elaboração de um inventário costuma seguir critérios técnicos objetivos e fundamentados na natureza histórica, artística, arquitetônica, sociológica, paisagística e antropológica, entre outros valores atribuíveis ao que se analisa. (MIRANDA, 2008, p. 77).

No caso dos conjuntos urbanos são avaliados os seguintes aspectos na perspectiva histórica da evolução espacial e das particularidades do acervo arquitetônico: o núcleo de fundação, as áreas de centralidade, setorizações, os eixos de expansão em relação ao território, os setores funcionais, pontos relevantes de visualização, dentre outras especificidades que corroborem a compreensão e contextualização do desenvolvimento da cidade estudada. É a partir desse grupo de informações que se estabelecem os parâmetros para a demarcação das poligonais de tombamento (e de seu respectivo entorno), áreas sobre as quais os órgãos preservacionistas exercerão suas atribuições de tutela.

A exemplo de Monte Santo, em áreas urbanas a definição das poligonais corresponde a demarcação cartográfica em desenho (Figura 2b) e a descrição textual a partir de elementos que permitam uma clara compreensão dos seus limites (IPHAN, 2011, p. 11).

Foram muitos os desafios transpostos pelos profissionais envolvidos nos estudos que instruíram o tombamento nacional de Monte Santo na década de 1980. Além da exiguidade de material fotográfico e precariedade da cartografia sobre a cidade com que contavam (o mapa de 1978 da Companhia de Eletricidade do Estado da Bahia - COELBA, único disponível até hoje), cabe mencionar a falta de legislação específica para proteção de "paisagens culturais"; um entendimento que só ocorreria oficialmente nos anos 2000.

A solicitação de tombamento deste sítio histórico se baseou no Decreto-Lei no 25/1937ix, artigo 1으, parágrafo 2o: "[...] paisagens de feição notável dotadas pela natureza ou agenciadas pela indústria humana [...]"x. A instrução baseada na "paisagem de feição notável" foi um artifício técnico por meio do qual procurou-se salvaguardar a dupla significação material e imaterial daquele grandioso monumento cultural do sertão baiano. "Nele estão definidos os limites do monumento, a área de proteção do monumento, o regime de propriedade na área preservada, mas também o arrolamento de imagens, quadros, coleção de ex-votos existentes no santuário e capelas e vários aspectos da cultura material" (IPHAN, 1983, p. 5)xi.

A zona de proteção estabelecida correspondeu a 735 hectares com "Grau de Proteção 01 (GP1) ${ }^{x i i}$, em que se inclui o conjunto urbano edificado a partir da cota de nível 500, a Via Sacra e toda área natural da serra dentro deste limite topográfico (Figura 2a).

Com a definição de uma poligonal que contorna a serra de Piquaraçá (patrimônio natural) e inclui o casario (patrimônio construído) das ruas mais antigas que conduzem ao início da Via Sacra, constitui-se uma área de proteção que incorpora acervo natural, paisagístico, urbanístico e arquitetônico. Com a delimitação dessa poligonal, evidencia-se a noção de ambiência e da valorização do núcleo urbano como patrimônio cultural, ao proteger as capelas devocionais e, por conseguinte, as manifestações religiosas seculares.

Não obstante seja conceitualmente estruturado em leituras morfológicas e espaciais, a abrangência do tombamento federal do Santuário da Santa Cruz não é totalmente inteligível nos documentos de registro elaborados no período pelos órgãos patrimoniais. 
Figura 3: a) Vista área de parte do conjunto urbano

tombado e do Sacro Monte, no qual se desenha a Via Sacra. b) Delimitação do tombamento, a partir da cota topográfica de nível

500.

Fonte: (a) Timóteo de Andrade Ferreira, 2019. (b)

Mapa de delimitação do sítio elaborado pelo MECSEC-SPHAN, 1982.

Figura 4: Modelo de Ficha de Inventário IPAC Ba usada para descrição dos bens imóveis. Frente e verso.

Fonte: Inventário de Proteção do Acervo Cultura da Bahia, Vol. VI, IPAC, Salvador, 1999.

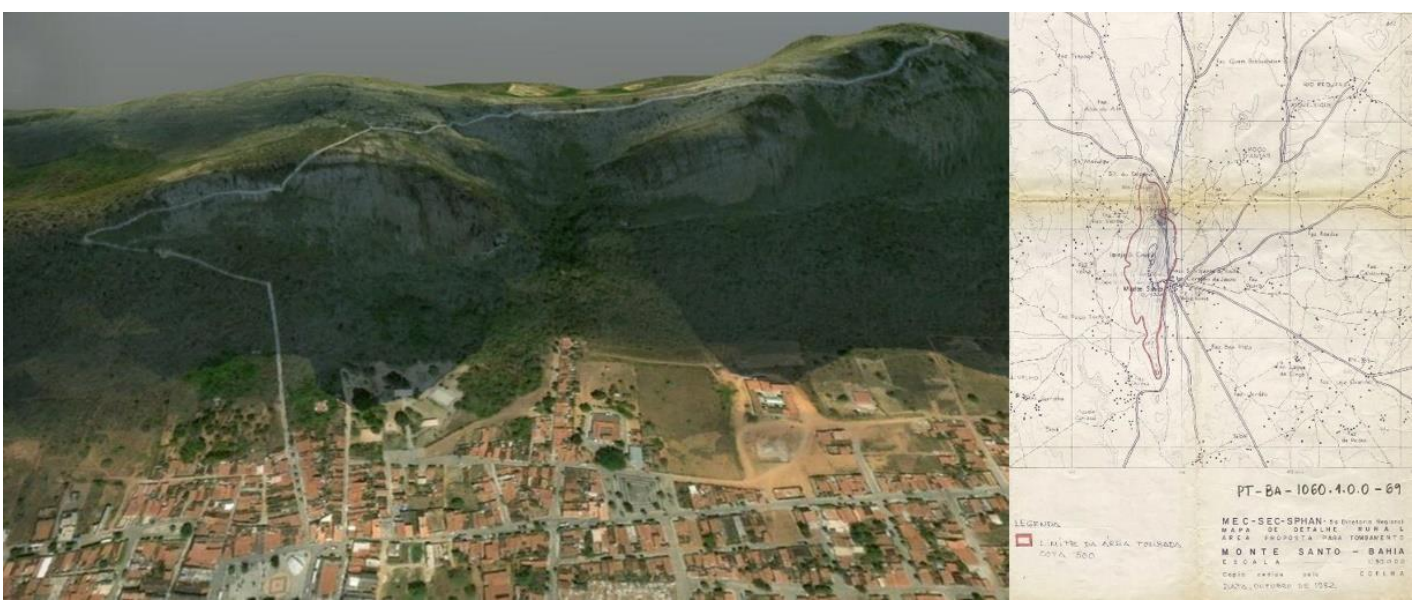

Apesar do inventário de Monte Santo ter englobado registros de peças de arte e incluido a proteção de inteiros logradouros, o maior número de documentos refere-se a identificação de exemplares da arquitetura histórica, por amostragem.Mas, a proposta e o formato de registro adotado para organizar as informações disponíveis não são suficientes para dar conta de um conjunto urbano com as características de Monte Santo na perspectiva da conservação integrada.

Nos parâmetros de valoração da época, cada bem arquitetônico considerado relevante naquela cidade foi localizado, identificado, avaliado e registrado em Fichas de Inventário compostas de duas sessões ("Fundamental" e "Dados Complementares"). A organização dos campos dessas fichas, por sua excelência, tornou-se modelo de referência em todo o país, sendo adotados até hoje para organizar descrições de bens imóveis, também em formatos digitais. A Ficha do IPAC-Ba é composta de duas sessões(Figura 4).

$\mathrm{Na}$ primeira parte organizam-se os dados sobre as características principais do bem: denominação, origem, situação e ambiência, uso, tipologia, técnicas construtivas, programa. Um pequeno grupo de imagens e desenhos técnicos (planta) representam a construção avaliada. Na segunda sessão são agrupadas informações sobre a importância histórica do bem estudado, sua delimitação de entorno, seu estado de conservação geral, dados sobre a propriedade, referências bibliográficas ,entre outros dados de interesse.
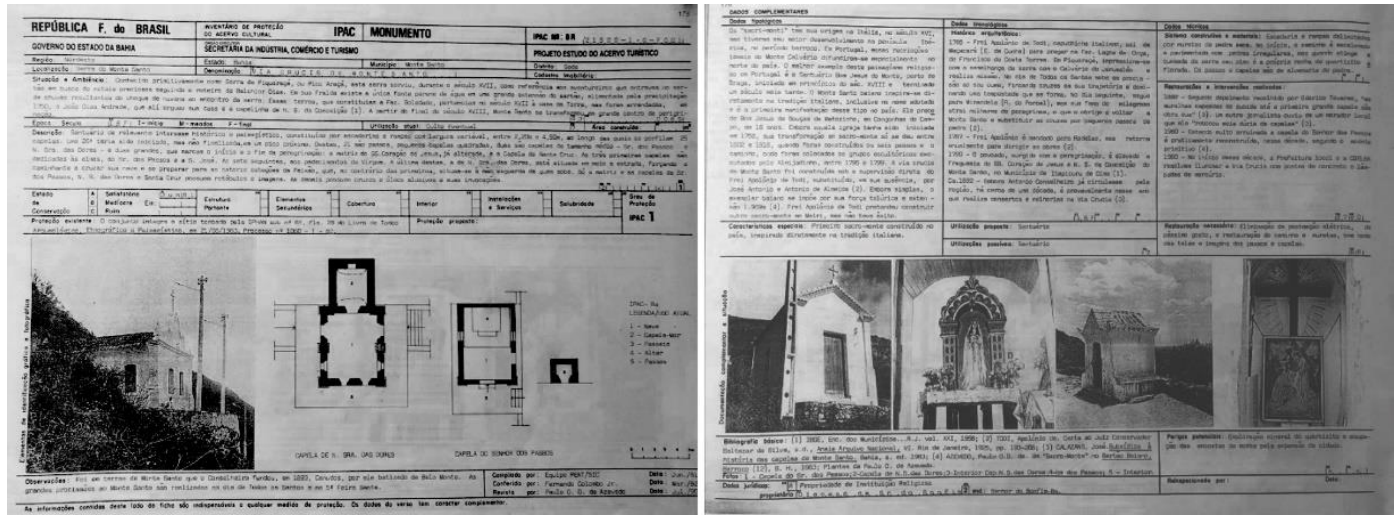

Uma questão essencial para a representação de arquiteturas preexistentes protegidas é a do "contexto", um elemento integrante nas especificações de tombamento que inclui proteção de vizinhança dos bens por meio da demarcação de áreas envoltórias, fixando parâmetros de visualidade para os objetos/conjuntos patrimonializados. No perímetro demarcado 
intervenções como novas construções, reformas, demolições, inserção de mobiliário urbano e outras alterações que possam interferir negativamente na percepção das relações de ambiência, devem ser monitoradas, em conformidade com as demais referências valorativas da conservação e do restauro.

Com efeito, a revisão dos modos de coleta de dados, armazenamento, representação e meios de difusão de inventários gerais de bens culturais brasileiros,tombados ou não, é ação necessária para aceder a boas formas de valorização do patrimônio cultural.

Em acordo com as prerrogativas preservacionistas contemporâneas, no âmbito de conjuntos urbanos, o levantamento e a representação das preexistências edificadas deveriam englobar tanto as características distintivas dos espaços originais como daqueles modificados. Núcleo histórico pode ser entendido como um conjunto de edifícios em que cada um deles tem seus próprios valores históricos e estéticos e que adquirem novos valores em escala urbana também em transformação contínua -na medida que estabelecem relações espaciais e figurativas recíprocas, difíceis de serem incorporadas em fichas descritivas.

Um dos caminhos para entender retroativamente a histórica e cultural do ambiente é a análise morfológica, que fornece ferramentas e categorias analíticas para avaliação dos processos de conformação e transformação dos elementos arquitetônicos e urbanos.

Neste sentido, aplicações digitais viabilizadoras de registros e análises de amplo espectro apresentam muitas outras potencialidades de pesquisa que podem contemplar a atualização da documentação do patrimônio urbano na complexidade requerida. Além dos atributos dos edifícios em diversas escalas e de suas condições de implantação, podem auxiliar no planejamento urbano das cidades e nos planos diretores, oferecendo-se como eficiente ferramental de trabalho; um apoio aos urbanistas para pensar adequadamente o papel das preexistências nas cidades contemporâneas.

\section{FLUXO DE TRABALHO PARA PLANEJAMENTO DO (RE) INVENTÁRIO: DA DOCUMENTAÇÃO CONVENCIONAL À PESQUISA PROSPECTIVA TRIDIMENSIONAL}

Arivaldo Leão Amorim conceitua a documentação arquitetônica "como um processo contínuo e sistemático de aquisição, tratamento, indexação, armazenamento, recuperação, publicação e divulgação de dados e informações gráficas e não gráficas, e seus metadados, sobre as edificações para os mais variados usos" (AMORIM, 2017, p.68). Incorporando essas diretrizes, nesta pesquisa, que visou subsidiar o reconhecimento preliminar das transformações do sítio no tempo, foram adotados procedimentos metodológicos que se alinham ao estudo da história da arquitetura e do patrimônio cultural.

As imagens provenientes de fontes variadas, realizadas em épocas e por autores diversos, no âmbito deste estudo foram consideradas registros fidedignos, basilares para estruturação do planejamento do processo de escaneamento 3D da arquitetura e espaços urbanos. Não existiria a hipótese de planejar um processo de (re) inventário da cidade, já tão alterada, sem análise acurada de documentos visuais e textuais anteriores.

Paralelamente as imagens fotográficas antigas foram examinadas referências textuais, diretas e indiretas sobre o território, incluindo-se obras literárias, entrevistas com arquitetos e técnicos que atuaram no inventário de identificação e tombamento de Monte Santo, pesquisas cartoriais e até mesmo obras cinematográficas, destacando-se aqui o filme "Deus e o Diabo na Terra do Sol", 1964, de Glauber Rocha.

A pesquisa desenvolveu-se em três etapas inter-relacionadas, a saber: 


\section{ETAPA 1: PESQUISA HISTÓRICA E ARQUIVÍSTICAS}

A análise crítico-comparativa de diferentes fases de desenvolvimento da cidade e alterações morfológicas correspondentes foi possibilitada pela consulta a diversos acervos públicos e privados, entre os quais mencionam-se: Museu do Sertão de Monte Santo - BA, Fundação Pierre Verger, Instituto do Patrimônio Histórico Artístico e Nacional da Bahia (IPHAN-BA), Instituto Patrimônio Artístico e Cultural da Bahia (IPAC-BA), Inventário de Proteção do Acervo Cultural da Bahia, Prefeitura Municipal de Monte Santo e arquivos privados de pesquisadores que se dedicam ao estudo da Guerra de Canudos.

\section{ETAPA 2: DEFINIÇÃO DE DESCRITORES HOMOGÊNEOS PARA PLANEJAMENTO DOS REGISTROS DIGITAIS E ANÁLISE}

A partir do exame crítico dos acervos iconográficos disponíveis, inferiu-se que as imagens realizadas pelo fotógrafo e antropólogo francês Pierre Verger (1902-1996) a partir da subida do Sacro Monte, em 1946, correspondem a registros da configuração mais antiga da cidade no século XX, que por sua vez coincidem com os espaços delimitados pela poligonal de tombamento, demarcada em 1983 pelo SPHAN.

Essas referências foram tomadas como base para a organização dos descritores de mensuração dos espaços/ edifícios, a saber: a)Análise das características da imagem pública da cidade na contemporaneidade; b) Determinação da relação entre a variedade de elementos e suas particularidades de integração urbana; c) Viabilização de registros detalhados das peculiaridades de cada imóvel (forma, perímetro, acabamentos, estado de conservação) presente nos logradouros tombados e no entorno correspondente a Praça da Igreja Matriz (área de interesse contígua);d) Realização de documentação digital primordial das construções presentes na Via Sacra, externa e internamente.

\section{ETAPA 3: DIGITALIZAÇÃO A LASER COMO FERRAMENTA DE LEVANTAMENTO}

Conforme já mencionado anteriormente, o laser scanner terrestre utilizado nos estudos de Monte Santo foi o FOCUS S70 da Faro. Este equipamento possibilita que os dados de varredura a laser possam ser facilmente importados nos softwares frequentemente usados no setor de Arquitetura, Engenharia, Construção e Operação (AECO). A precisão da distância deste equipamento é de até $\pm 3 \mathrm{~mm}$, alcance de 0,6 a $70 \mathrm{~m}$, classe IP54, câmera acoplada, sobreposição de fotos HD coloridas de até 165 megapixels, com panoramas esféricos.

A tecnologia LiDAR (Light Detection And Ranging) do scanner Faro favorece a agilidade das capturas.Trata-se de um sistema que funciona por pulso de laser, que emite radiação eletromagnética em ondas curtas $(1-10 \mu \mathrm{m})$, um sensor ativo que captura e emite dados (GIONGO et al., 2010, p. 232).0 equipamento calcula qual o tempo a luz demorou para ir até o alvo e voltar para o sensor, gerando através dos pontos atingidos pelos pulsos do laser a nuvem de pontos.

\section{ASPECTOS METODOLÓGICOS DA AQUISIÇÃO DE DADOS COM O 3D LASER SCANNING}

A partir do reconhecimento seguro de estágios anteriores da evolução da cidade, considerouse a área demarcada pela poligonal de tombamento baseada em cota de nível topográfico 
(Figura 5a) para pré-definir um "mapa chave" das áreas e pontos de interesse para o escaneamento. 0 levantamento de campo realizado com o 3D Laser Scanner contemplou as seguintes etapas: 1) Planejamento; 2) Aquisição de dados digitais; 3) Pré-processamento; 4) Processamento.

As estações estabelecidas para realização das varreduras do laser scanner tiveram início no Largo da Matriz (área de entorno) prosseguindo para o núcleo arquitetônico e arruamento urbano ao sopé da serra, para a seguir estender-se às construções da Via Sacra, edificadas no morro em aclive a partir da cota topográfica 500 , ao longo de $2 \mathrm{~km}$.

\section{PLANEJAMENTO}

Correspondeu a 3(três) sequenciamentos definidos no âmbito do perímetro interno da poligonal de tombamento, a saber:

1. As varreduras da Praça Matriz Monsenhor Berenguer incluiram todas as testadas de quadra que a perfazem (Figura 2): a Igreja Sagrado Coração de Jesus e casario dos logradouros adjacentes a Praça que correspondem ao entorno protegido do núcleo tombado.

2. Os cinco logradouros ao pé da serra de Piquaraçá e todo seu casario. Neste trecho, para reduzir ao máximo as zonas de sombras (oclusões), fixou-se $10 \mathrm{~m}$ de distância máxima entre os pontos de varreduras para cobrir toda a área de interesse, correspondente as cinco ruas protegidas incluindo-se um novo arruamento, a Rua Dois de Julho, que não constava nos registros de tombamento (Figura $5 \mathrm{~b}$ ).

3. A Via Sacra e suas capelas, incluindo as igrejas de Nossa Senhora das Dores (Figura 6) e a Igreja do Calvário (Figura 7).

\section{FASE DE AQUISIÇÃO DE DADOS}

No equipamento foi adotada como parâmetro precisão $+-3 \mathrm{~mm}$ e densidade única, para evitar erros de informação. Para registro de dados nestes locais utilizando-se o software Scenexiii da FARO, foi ativado o Sistema de Posicionamento Global (GPS) para registro das varreduras/cenas que formam a "nuvem de pontos" (modelos parciais), consolidada em um único sistema de coordenadas (geodésico) e controle da precisão dos resultados.

Com estes procedimentos realizaram-se 126 varreduras a laser em todo o conjunto correspondente aos três agrupamentos de espaços/construções pré-definidos. No grupo da Praça da Matriz (1) e nos logradouros/casario tombados (2) foram executadas 96 tomadas que totalizam área de $428.000 \mathrm{~m}^{2}$. Na Via Sacra foram executadas 30 varreduras, uma área equivalente a $600 \mathrm{~m}^{2}$.

\section{FASE DE PRÉ-PROCESSAMENTO}

Correspondeu à segmentação, geração de modelo preliminar, otimização, edição e conversão de arquivo para análise e reprodução gráfica, aplicando-se os seguintes recursos:

-Filtro de objetos em movimento: Remoção automática de objetos indesejados e capturas de movimentos durante a digitalização, como pessoas ou veículos.

-Manipuladores de malha: Os manipuladores de malha constituídos de alavancas de translação e rotação possibilitam o manuseio da inserção da cena ou grupo de cenas na implantação urbana. Esse procedimento possibilitou a reconstituição volumétrica de inteiros trechos do centro tombado (Figura 5d). 
Figura 5: a) Logradouros tombados do núcleo histórico. b) Registro de dados digitalizados deste local em tratamento para geração de nuvem de pontos. Divisão em dois grupos para geração de modelo completo do conjunto

urbano: em verde, trecho correspondente ao entorno do núcleo tombado (Praça e Igreja do Sagrado Coração de Jesus); em vermelho, casario e logradouros ao sopé da serra protegidos legalmente. c) Mapa das estações das 96 varreduras no núcleo e entorno d) Parte do sítio em processo de modelagem para produção de informações gráficas (parte de Rua Senhor dos Passos e Rua Barão de Jeremoabo), visualizada através do software Revit.

Fonte: (a) Mapa chave do casario urbano, IPAC-Ba 1999; (b/c/d) Elaborado por Timóteo de Andrade Ferreira, 2019.
-Redigitalização de objetivos distantes: Correspondeu a varredura de áreas distantes que precisavam ser digitalizadas com maior resolução, para reconhecimentos dos objetos com maior precisão de detalhes. Deste procedimento resultaram registros detalhados de elementos de fachada, a serem modeladas e estudadas em fase subsequente desta pesquisa.

- Exportação de imagens panorâmicas de alta resolução: Exportação e importação de modelos 3D nos formatos .obj. A função Export. Obj permitiu a inclusão de malhas texturizadas nas quais foram exportadas uma seção de uma nuvem de pontos de Scene manipulada a seguir no ReCap ${ }^{x i v}$, possibilitando exportação de trechos pontuais, análise de detalhes e imagens de cada cena realizada em alta resolução.

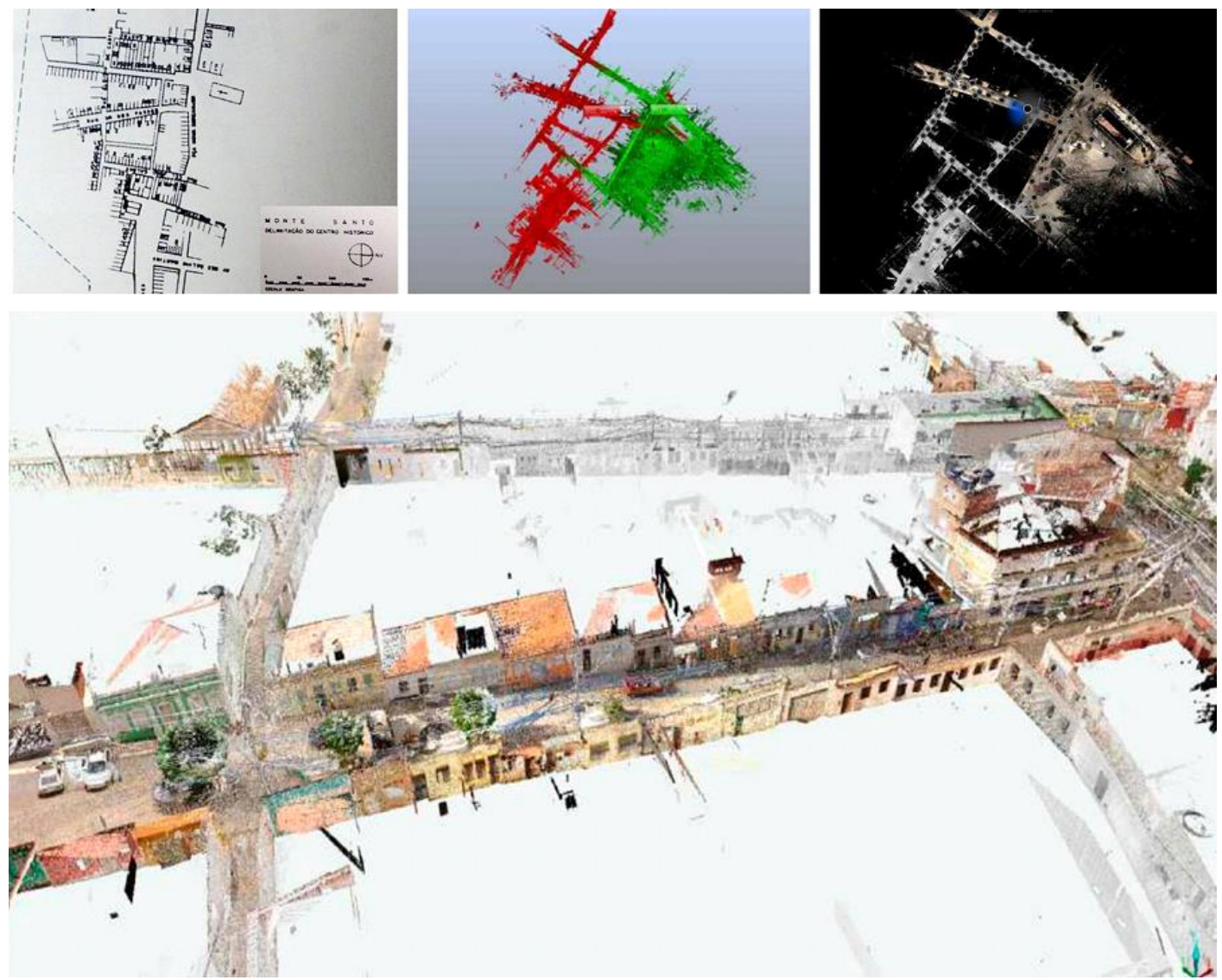

\section{PROCESSAMENTO}

A partir do registro e digitalização dos dados iniciou-se a etapa de processamento gerando o modelo basilar de nuvem de pontos, exportáveis para plataformas CAD e BIM, programas para animação, rendering, simulação, realidade virtual, realidade aumentada, impressão 3D, prototipagem rápida, fabricação digital, entre outros. Neste estudo de caso, em acordo com a proposta de registro global, correspondente a uma "prospecção tridimensional "inicial do nucleo urbano de Monte Santo, foi adotado o programa REVIT para produção de desenhos e informações gráficas basilares, utilizando-se a modelagem BIM "Nível de Desenvolvimento" LOD100 ${ }^{\mathrm{xv}}$. 

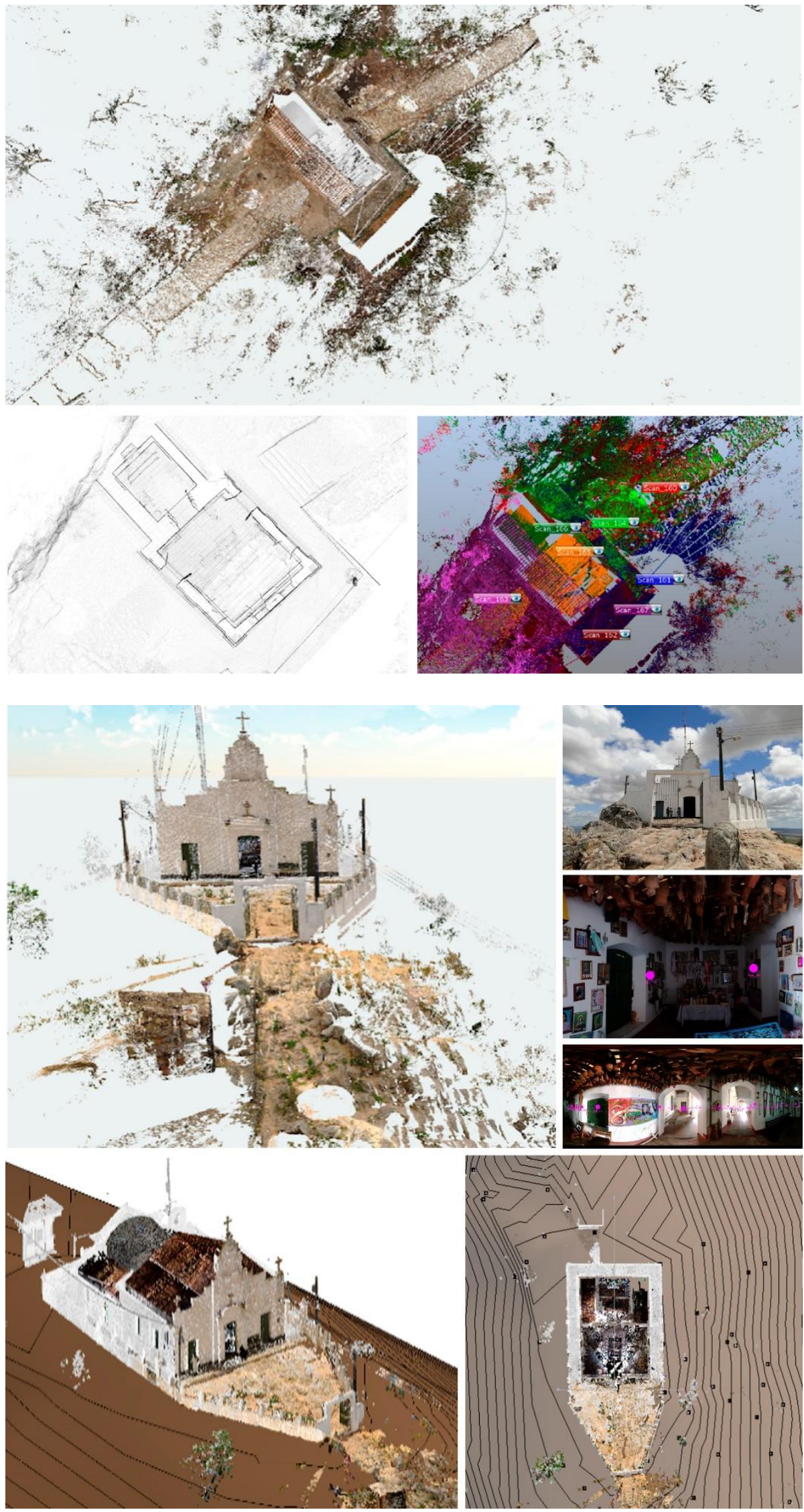

Figura 6: Igreja Nossa Senhora das Dores, no trecho intermediário da Via Sacra. a) Modelo observados a partir de nuvem de pontos - vista planar. b) Vista em seção horizontal do modelo tridimensional gerada através do RECAP. c) Via Sacra e grupo de varreduras no SCENE.

Fonte: $(\mathrm{a} / \mathrm{b} / \mathrm{c})$ Timóteo de Andrade Ferreira, 2019.

Figura 7: Documentação gráfica gerada no processo de tratamento da nuvem de pontos:planta, inclusão de modelo em curvas de nível,visualizações de elementos internos e externos da igreja para publicações on line.

Fonte: (a/b/c/d/e/f) Elaboraçao Timóteo de Andrade Ferreira, 2019. 
Com a consolidação da nuvem de pontos e digitalização de dados obtiveram-se produtos possibilitadores das primeiras análises das permanências e alterações do lugar: visualização tridimensional dos objetos escaneados através da nuvem de pontos, interface com os softwares ReCap e REVIT, visualização "on-line" dos conjuntos edificados, extração e aferição de medidas e identificação das variadas características construtivas e ornamentais das edificações históricas, além da possibilidade de inserção de curvas de níveis, conforme exemplificado nas Figuras 6 e 7.

\section{APLICAÇÃO E UTILIZAÇÃO DE 3D LASER SCANNING: VANTAGENS E POSSIBILIDADES}

As áreas de aplicação da tecnologia LiDAR não se restringem ao levantamento arquitetônico, mas podem incorporar também a escala urbana e territorial ao possibilitar sistemas de varreduras fixas ou móveis.

Entre as principais vantagens do equipamento de laser scanner utilizado neste estudo destacam-se: a possibilidade de aquisição rápida de grande quantidade de dados digitais; excelente precisão e acurácia das informações coletadas; alta resolução dos pontos detectados; amplitude de campo de visão $\left(360^{\circ}\right.$ eixo vertical x $300^{\circ}$ eixo horizontal);obtenção de digitalizações em cores de excelente qualidade possibilitada por câmera coaxial a cores acoplada no equipamento.

Contudo, apesar da automação das ferramentas LiDAR facilitarem sobremaneira o trabalho de escaneamento do patrimônio edificado, para a obtenção de resultados eficientes alguns fatores devem ser levados em consideração. Os custos operativos são altos, sendo conveniente planejar precisamente os levantamentos de campo e o processamento dos dados do equipamento. 0 planejamento deve considerar as características do local do levantamento (condições meteorológicas e climáticas), as condições de luminosidade e do material das superfícies ou áreas de levantamento; as possibilidades de operações de manuseio do instrumento em relação ao objeto/área a documentar, considerando o alcance, a velocidade de varredura adequada, a resolução baseada na definição do grau de precisão a ser obtido e as etapas de processamento e produtos esperados.

Com os dados digitais reunidos na nuvem de pontos gerada nesta experiência planejada de "prospecção tridimensional" para reconhecimento global do núcleo tombado de Monte Santo na contemporaneidade, delinearam-se diversas outras possibilidades de estudos técnicos do patrimônio edificado do sítio que integrarão novas pesquisas específicas no âmbito do LCORArquitetura da Unicamp.xvi

Estão previstos estudos cromáticos e texturais dos elementos, objetos e edifícios escaneados, avaliando-se características dos materiais constitutivos e patologias típicas das construções mais antigas; modelos volumétricos texturizados de edifícios exemplares para estudos técnicos e formais e reconstituição digital das testadas de quadra para análise da evolução tipológica do conjunto arquitetônico (nunca estudada);reprodução gráfica em desenho de objetos, edifícios e conjuntos urbanos; utilização de nuvem de pontos para produtos de realidade aumentada objetivando maior extroversão pública do patrimônio arquitetônico e artístico do local; realização de modelos digitais (em processamento)dos edifícios religiosos da cidade e do monte sacro e vistas planares da nuvem para usos educacionais e ampla difusão. 


\section{CONCLUSÕES}

Com o intuito de colaborar com a atualização das informações reunidas décadas atrás sobre o núcleo tombado de Monte Santo, essa pesquisa representou etapa de recolha sistemática de dados que ao associar documentos arquivísticos e iconográficos à levantamentos métricos e imagéticos auxiliados por equipamentos digitais de alta performance possibilita diversas abordagens do patrimônio edificado deste e de outros sítios históricos.

É consenso que a documentação tridimensional (3D) abrangente de locais culturalmente importantes se oferece a uma grande variedade de propósitos, podendo auxiliar na conservação e restauração de estruturas edificadas, no gerenciamento, no aprofundamento de estudos de história urbana, em procedimentos educacionais interessantes e fundamentados que dão a conhecer o patrimônio para estudiosos e público em geral. Contudo, se por um lado os dados adquiridos constituem-se em uma categoria de preservação digital, uma representação virtual atemporal da estrutura as-built, por outro, o reconhecimento da qualidade e abrangência das "novas feições" que Monte Santo adquiriu no tempo coloca-se como aspecto fundamental para planejamento de ações capazes de assegurar a permanência dos valores culturais que efetivamente caracterizam a cidade. Este é o grande desafio que demanda ampliação de leitura sobre sítios tombados de modo que projetos de estudo ou intervenção possam acolher mais que expressões estéticas.

Estudos de inventariação de áreas urbanas precisam incorporar o dinamismo da cultura em favor de avaliações integradas, que considerem as relações dos bens estudados com as mutações do contexto histórico, natural e edificado em que se insere. É preciso que acolham pesquisas contínuas e multidisciplinares, possibilitadoras de revisões e atualizações das informações, de modo a promover comunicação efetiva entre os distintos órgãos administrativos envolvidos na gestão e tutela do patrimônio.

Considera-se ainda que a visualização tridimensional de extensas áreas do núcleo histórico de Monte Santo e de seu Sacro Monte - algumas de difícil acesso - possibilitada por cerca de 900 milhões de pontos captados pelo laser scanner (ainda em processamento), é por si uma significativa ação preservacionista. Em 2019, no decurso desta pesquisa, a igreja da Praça da Matriz da cidade, que nunca havia sido desenhada antes, foi vitimada com um incêndio de médias proporções, felizmente debelado. São bastante conhecidos os casos brasileiros de sítios e monumentos inexoravelmente destruídos por desastres naturais ou antrópicos, que nos legam ruínas ou melancólicas reconstruções em "estilo antigo" por falta de levantamentos e registros imagéticos fidedignos. Nossa herança cultural está constantemente submetida a situações de risco, indicando a necessidade (e premência) de atualização e aperfeiçoamento de nossas sistemáticas de documentação, com investimento em tecnologia e em pessoal qualificado para processá-las.

Com os dados reunidos, espera-se contribuir com um processo de (re) inventariação de Monte Santo, a ser aprimorado e desdobrado futuramente em projetos multidisciplinares associados ao campo da preservação cultural. Eles hão de ser possibilitados.

\section{Agradecimentos}

À Kemp Projetos e Gerenciamento, São Paulo, Brasil, pela gentil cessão do equipamento Laser Scanner 3D em apoio e incentivo a pesquisas acadêmicas do Programa de Pós Graduação Arquitetura, Tecnologia e Cidade da Unicamp na área do patrimônio cultural. 
Aplicações de 3D laser scanning para um (re) inventário digital do patrimônio cultural edificado de Monte Santo, Bahia.

\section{Referências Bibliográficas}

ALMEIDA, F.; TIRELLO, R. A. Tecnologias computacionais: aplicativos multimídia para registro e difusão do patrimônio histórico arquitetônico. CIDADE E INDÚSTRIA: Ações Contemporâneas; 3으 Seminário do Programa de Pós-Graduação em Arquitetura e Urbanismo da USJT, 3., 2009, São Paulo. In: Anais... São Paulo: USJT, 2009. v. 1, p. 1-12.Disponível em: <https://www.researchgate.net/publication/342515911_TECNOLOGIAS_COMPUTACIONAIS_aplica tivos_multimidia_para_registro_e_difusao_do_patrimonio_historico_arquitetonico>. Acesso em nov. 2020.

AMORIM, A. L. A documentação arquitetônica como uma atividade multi, inter e transdisciplinar. In: Ponto de Acesso, Salvador, v.11, n.1, p. 61-84, 2017. Disponível em:

< https://periodicos.ufba.br/index.php/revistaici/article/view/23176/14681>.Acesso em out.2020.

BRASIL. Constituição (1988). Constituição da República Federativa do Brasil. Brasília, DF: Centro Gráfico, 1988, p. 126. Disponível em:

<https://www2.senado.leg.br/bdsf/bitstream/handle/id/518231/CF88_Livro_EC91_2016.pdf>. Acesso em Out. 2020.

BRASIL, IPAC. Inventário de Proteção do Acervo Cultural - vol. VI. Monumentos e Sítios das Mesorregiões do Nordeste, Vale Sanfranciscano e Extremo Oeste da Bahia, Governo do Estado da Bahia / Secretaria da Indústria e Comércio / Coord. do fomento ao turismo, Salvador, 1999, p. 169180.

BRASIL, IPHAN. Normatização de Cidades Históricas. Edição: 2010, p. 11. Publicação: Iphan. Acesso digital. Disponível em:

<http://portal.iphan.gov.br/uploads/publicacao/normatizacao_areas_tombadas_cidades_historicas _2011.pdf>. Acesso em ago. 2020.

GIONGO, M.; KOEHLER, H. S.; MACHADO, S. do A.; KIRCHNER, F. F.; MARCHETTI, M. LiDAR: princípios e aplicações florestais. Pesquisa Florestal Brasileira, [S. I.], v. 30, n. 63, p. 231-244, 2010, p. 232. DOI: 10.4336/2010.pfb.30.63.231.

Disponível em: <https://pfb.cnpf.embrapa.br/pfb/index.php/pfb/article/view/148>. Acesso em out. 2020.

ICOMOS: Principles for ther recording of monuments, groups of buildings and sites (1996). Disponível em <icomos.org/charters/archives-e.pdf> Acesso set. 2019.

ICOMOS: Carta de Veneza. II Congresso Internacional de Arquitetos e Técnicos dos Monumentos Histórico (1964). Disponível em http://portal.iphan.gov.br/uploads/ckfinder/arquivos/Carta\%20de\%20Veneza\%201964.pdf> Acesso em dez. 2020.

MIRANDA, M. P. de S. O inventário como instrumento constitucional de proteção ao patrimônio cultural brasileiro. Revista Jus Navigandi, ISSN 1518-4862, Teresina, ano 13, n. 1754, 2008, p. 77.

Disponível em: <https://jus.com.br/artigos/11164>. Acesso out. de 2020.

RABELLO, Sonia. O tombamento. In: REZENDE, Maria Beatriz; GRIECO, Bettina; TEIXEIRA, Luciano; THOMPSON, Analucia (Orgs.). Dicionário Iphan de Patrimônio Cultural. Rio de Janeiro, Brasília: Iphan/DAF/Copedoc, 2015. (Termo chave Tombamento). Disponível em: < https://bit.ly/2OnOaRI >. Acesso em: dez. 2019.

TEIXEIRA, Luciano; THOMPSON, Analucia (Orgs.). Dicionário IPHAN de Patrimônio Cultural. 1a ed. Rio de Janeiro, Brasília: IPHAN/DAF/Copedoc, 2015, p. 77. ISBN: 978-85-7334-279-6. 
UNESCO. Operational guidelines for the implementation of the world heritage convention. Paris: UNESCO, 2005, p. 14. Disponível em:

<https://en.unesco.org/creativity/sites/creativity/files/passeport-convention2005-web2.pdf>

Acesso em ago. 2020

VIEGAS C. C. L.; TEIXEIRA, R. B. O papel da ambiência histórica nos processos de tombamento de Sítios Históricos Urbanos. In: Cadernos de História, Belo Horizonte, v. 18, n. 28, 1o sem. 2017, p. 28; ISSN 2237-8871, DOI: 10.5752/P.2237-8871

Processos e documentos:

IPAC. Inventário de Proteção do Acervo Cultural da Bahia. Salvador: Governo do Estado da Bahia. Salvador. v. 6. 1999.

IPHAN/Processo № 1.060-T-82 S.P.H.A.N./D.T.C. Fundação Nacional pró-memória/Divisão de Registro e Documentação, 1983. p. 4.
Regina Andrade Tirello rtirello@unicamp.br

Timóteo de Andrade Ferreira andradetimote01@gmail.com

\title{
Notas
}

\begin{abstract}
' Documento da 11a Assembleia Geral do Icomos, em Sofia, Bulgária, em 1996: Principles for the recording of monuments, groups of buildings and sites (1996).Disponível em <icomos.org/charters/archives-e.pdf>. Acesso em set. de 2019.

ii Instituto do Patrimônio Histórico e Artístico Nacional.

iii Pesquisa de mestrado intitulada "Aos pés do Altar do Sertão têm uma cidade a preservar: Monte Santo da Bahia", desenvolvida no Programa de Pós-Graduação em Arquitetura, Tecnologia e Cidade da Universidade Estadual de Campinas (Pós ATC-Unicamp). Autor: Timóteo de Andrade Ferreira. Orientadora: Profa. Dra. Regina Andrade Tirello, 2020.

iv O Faro FOCUS S70 foi cedido pela empresa Kemp Projetos e Gerenciamento em apoio a pesquisas acadêmicas sobre patrimônio construído que vêm sendo desenvolvidas por integrantes do LCORArquitetura (Unicamp) em trabalhos associados a pesquisas no âmbito do Programa de PósGraduação Arquitetura, Tecnologia e Cidade (ATC) da Universidade Estadual de Campinas sob orientação da profa. Regina A. Tirello.

v Processo no 1060-T-82. Inscrição no Livro do Tombo Arqueológico, Etnográfico e Paisagístico sob no 85, conjunto Arquitetônico, Urbanístico, Natural e Paisagístico, 21 de junho de 1983.

vi Constituição da República Federativa do Brasil, Art. 216:"Constituem patrimônio cultural brasileiro os bens de natureza material e imaterial, tomados individualmente ou em conjunto, portadores de referência à identidade, à ação, à memória dos diferentes grupos formadores da sociedade brasileira".

vii O Inventário de Proteção do Acervo Cultural da Bahia (IPAC-Ba) é composto por 7 volumes. Os estudos da cidade de Monte Santo integram o Volume VI - Monumentos e Sítios das Mesorregiões do Nordeste, Vale Sanfranciscano e Extremo Oeste da Bahia. BAHIA. Secretaria da Indústria e Comércio. IPAC-BA: Inventário de Proteção do Acervo Cultural da Bahia. Salvador: Secretaria da Indústria e Comércio, 1975-2002. 7v.

viii Canhão inglês Withworth de 32 libras do exército brasileiro, apelidado pelos sertanejos de "a Matadeira", que foi transportado por vinte juntas de bois através do sertão, tendo disparado um único tiro no confronto.

ix O Decreto-Lei no 25, de 1937, foi promulgado com a finalidade de organizar e proteger o patrimônio histórico e artístico nacional. Disponível em <http://portal.iphan.gov.br/uploads/legislacao/Decreto_no_25_de_30_de_novembro_de_1937.pdf> Acesso em ago.de 2019.
\end{abstract}


“Em agosto de 2000 o Decreto $n^{\circ} 3.551$, institui o "Registro de Bens Culturais de Natureza Imaterial” do patrimônio cultural brasileiro, criando o Programa Nacional do Patrimônio Imaterial.

xi IPHAN, 21 de junho de 1983, Processo $n^{\circ}$ 1060-T-82 inscrito no livro do Tombo Arqueológico, Etnográfico e Paisagístico.

xii Grau de Proteção 01 (GP1). Proteção rigorosa, aplicável aos edifícios de importância histórica e/ou arquitetônica relevantes para o conjunto urbano. Os aspectos originais de sua concepção de vem ser mantidos integralmente.

xiii O software Scene da FARO, foi desenvolvido especificamente para os lasers scanners Focus Freestyle. Processa e gerencia dados usando os recursos de registro no local em tempo real. Ocorre reconhecimento automático de objetos, posicionando e registrando as digitalizações.Disponível em < https://www.faro.com/pt-br/produtos/product-design/faro-scene/> Acesso em abr. 2019.

xiv $\mathrm{O}$ ReCap permite criar modelos 3D a partir de fotografias ou digitalizações a laser. O produto final é uma nuvem de pontos ou malha pronta para ferramentas de criação CAD e BIM. Mais informações disponíveis em<https://www.autodesk.com/products/recap/features> Acesso em abr. 2019.

xv O Level of Development - LOD, classificação sugerida pelo American Institute of Architects (AIA) para organizar as etapas do desenvolvimento de um empreendimento em BIM. No "Project Building Information Modeling Protocol",2013, o AIA define 5 níveis de LOD, que possibilita determinar as informações necessárias em cada etapa de um trabalho.

xvi LCOR-Arquitetura/Unicamp-Laboratório de Conservação e Restauro da Arquitetura e Sítios da Faculdade de Engenharia Civil, Arquitetura e Urbanismo da Universidade Estadual de Campinas. 